\title{
Long-term Test Arrangement for Externally Strengthened Reinforced Concrete Elements
}

\author{
T. Vaňura, P. Štěpánek, I. Švaříčková, J. Adámek
}

\begin{abstract}
Methods for extermal strengthening of concrete use elements of very high tensional strength glued on to its tensioned surface. These elements may be of metal, carbon fibers (CFRP), glass fibers or others, usually having very good mechanical properties. However, these high-strength elements are normally attached to concrete by epoxy resins. Epoxy resins have a low Young's modulus and therefore a higher rate of creep may have an influence on the long-term behavior of such external strengthening. In order to verify this idea experimentally a special space-saving arrangement of tests is described in this paper. Panels act as loaded beams but simultaneously as a load for the other panels in a stand. The different load magnitude acting on a different layer of panels should make it possible to study the long-term influence of the degree of shear force on the glue creep. Certainly, the glue creep may be dependent on the type of epoxy resin; therefore several epoxy resin types are included in the tests.
\end{abstract}

Keywords: carbon fiber (CFRP), glass fiber (GFRP), external strengthening, epoxy-resin creep, test arrangement.

\section{Notation}

$G \quad$ weight of load

$g \quad$ self-weight of panel

$G_{0} \quad$ weight of extension piece

$V_{0} \quad$ vertical load action

$V_{k} \quad$ vertical support action

$M \quad$ bending moment

$\ell_{0} \quad$ span

a coefficient

$\gamma \quad$ ratio of increments of moments

\section{Introduction}

Because of the durability of concrete structures, many of them were designed for lighter live loads than are common today. Strengthening of some their components has therefore become necessary. Certainly other reasons for such strengthening may also arise, e.g., partial damage, etc.

Steel plates, composite lamellas (plates) or glass-fabric strengthening are used for such reinforcement. They are glued by very effective adhesives on to tensioned surface of the structure.

Today's adhesives, i.e., epoxy resins mostly, enable satisfactory gluing of the strengthening elements on a construction site. However, climatic and humidity conditions should be taken into account. The experiments described in this paper were prepared in laboratory conditions, although in the case of the glass-fabric strengthening the gluing overhead without mat supporting was successfully put to the test (see [2]).

There remains the separate problem of perfect bonding of the strengthening element to the structure surface, which means no slip between the strengthening element and the concrete. According to the test results reported in [1] and also those achieved by ourselves (mentioned in the following text), this assumption need not be necessarily completely satisfied.
A special test arrangement focused on adhesive creep monitoring is described in this paper.

\section{Conclusions from previous tests}

In conjunction with short-term-load tests [2], long-term-load tests of three remaining strengthened panels were started, with the aim of evaluating the long-term behavior of glued fiberglass strengthening in natural open air weather conditions under constant load. The duration of these tests was 14 months.

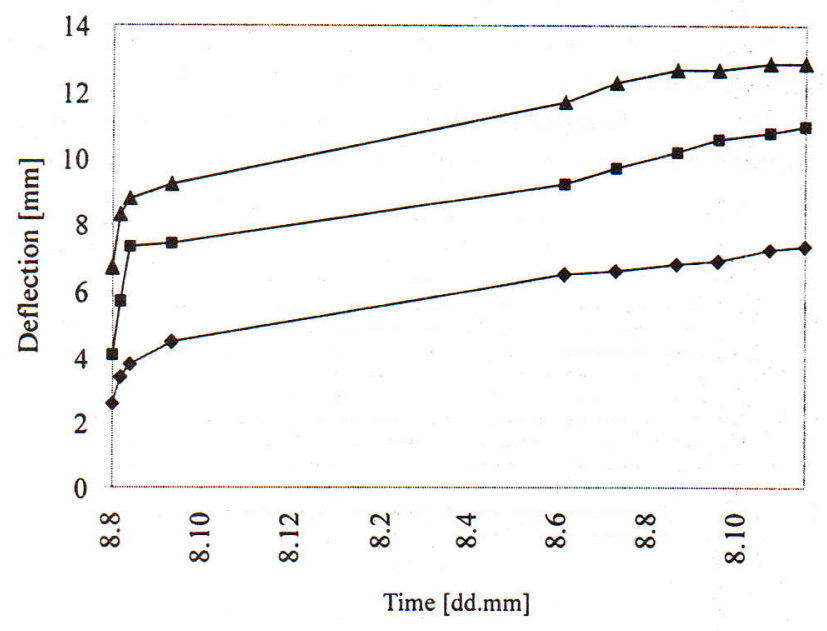

Fig. 1: Time dependent deflections of three panels strengthened with a glass-fiber mat [2] under different load magnitudes

The load position of two solitary forces was in one third of the span of each panel, but the strength of the load was different for each of them. The deflections of the tested panels grew continually, as follows from Fig. 1. Due to illness there was an almost nine month gap in measurements (as shown in Fig. 1). The time behavior of the deflections indicates the suspicion of possible continuous horizontal displacement of the glass laminate course against the concrete surface. The tested 
panels were 18 months old when the long-term-load tests started. Therefore concrete creeping probably was not the main reason for the displacement growth.

The problem of epoxy-resin creep in strengthening connections has come under the spotlight in tests now going ahead at the Technical University in Brno.

\section{Special long-term test arrangement on strengthened concrete panels}

Fig. 2 shows the constitutive idea of a special space-saving arrangement of tests scheduled for a minimum of three years.

The panels in the stand in Fig. 2 act as loaded beams, but simultaneously act as a load for the other panels. The different load magnitude acting on a different layer of panels should make it possible to study the long-term influence of the degree of shear force on the glue creep. The glue creep may be dependent on the type of epoxy resin; therefore several types of epoxy resin are included in the tests. Altogether six stands with different combinations of adhesive and strengthening material have been built up in the open air.

This arrangement should ensure a regular step-up of the bending moments and also the shear forces in each layer of the stand. For this purpose, some comparative calculations have been made to determinate the right magnitudes of the span of supports $\ell_{0}$ and also of coefficient $\alpha$. The following relations have been used in these calculations:

Vertical load action

$$
V_{0}=G / 2 \text {. }
$$

Support action

$$
V_{k}=V_{0}+k\left(G_{0}+\frac{1}{2} g \ell\right) \quad k=1, \ldots, 5 .
$$

Forces $V_{0}$ act downward on the top of each of the two highest extension pieces (supporting the load). Forces $V_{k}$ $(k=1, \ldots, 5)$ act upward on the top of each of extension piece (supporting the panels) in the five lower layers.

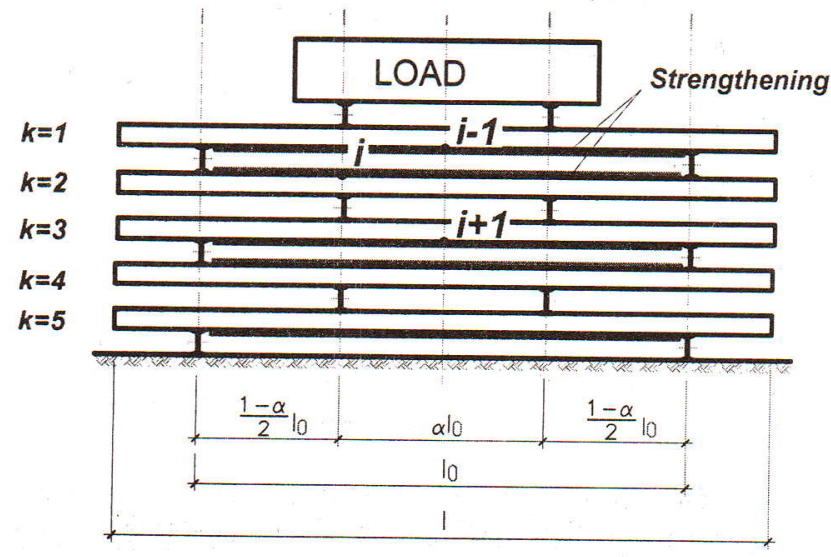

Fig. 2: Long-term test arrangement for a survey of adhesive creep $\left(2^{\text {nd }}\right.$ and $4^{\text {th }}$ layer lie upside down)

Maximum positive moment at the midpoint of the span $k=1,3,5$ :

$\max M_{k}=\frac{1}{2} V_{k} \cdot \ell_{0}-\frac{1}{2} g\left(\frac{\ell}{2}\right)^{2}-\left(V_{k-1}+G_{0}\right) \frac{\alpha \cdot \ell_{0}}{2}$.
Maximum negative moment above the support $k=2,4$ :

$\min M_{k}=-\left(V_{k-1}+G_{0}\right) \frac{1-\alpha}{2} \ell_{0}-\frac{1}{2} g\left(\frac{\ell-\alpha \cdot \ell_{0}}{2}\right)^{2}$.

Negative moment at the midpoint of the $\operatorname{span} k=2,4$ :

$$
M_{k 0}=-\left(V_{k-1}+G_{0}\right) \frac{1}{2} \ell_{0}-\frac{1}{2} g\left(\frac{\ell}{2}\right)^{2}+V_{k} \frac{\alpha \cdot \ell_{0}}{2} \text {. }
$$

When evidently $\left|M_{k 0}\right|<\left|\min M_{k}\right|$.

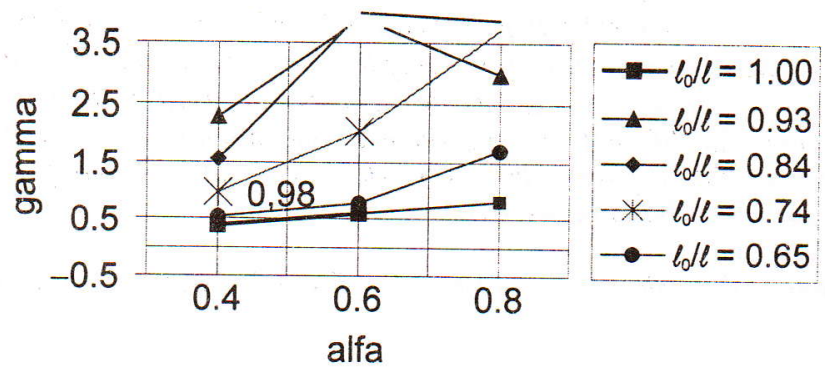

Fig. 3: Optimization result of the span of supports $\ell_{0}$ and also of coefficient $\alpha$

A simple handy computer program has facilitated the calculation of a large number of possibilities, and the results of these calculations can be evaluated from Fig. 3 .

Magnitude $\gamma$ in Fig. 3 has the meaning of a ratio of increments of bending moments in subsequent layers of panels in the stand, and is mathematically expressed by a relation (with respect to the notations in Fig. 2): Relation (6) is meaningful if it is written for layers $i=k=2$ and $i=k=4$.

$$
g=\left|\frac{M_{i+1}-M_{i}}{M_{i}-M_{i-1}}\right| \Rightarrow 1
$$

Optimally this ratio should be equal to 1 , and the nearest value to this in the graph in Fig. 3 is the value $\gamma=0.98$ for $\ell_{0} / \ell=0.74$ and $\alpha=0.40$.

Consecutively if $\ell_{0} / \ell=0.74$, i.e., for $\ell=5.38 \mathrm{~m}$, $\ell_{0}=4.00 \mathrm{~m}$ and for $\alpha=0.42$ the distance $\alpha \cdot \ell_{0}=1.68 \mathrm{~m}$, then the increments of bending moments in subsequent layers of panels with gravity load $g=8.18 / 5.38=1.52 \mathrm{kNm}^{-1}$ and weight of extension pieces $G_{0}=0.245 \mathrm{kN}$ equals close to $\gamma \approx 5 \mathrm{kNm}$ (slightly rounded off). The increment of the shear force follows from equation (2) and under these conditions equals $4.34 \mathrm{kN}$.

The magnitudes of both increments are independent of the magnitude of the load.

\section{Measurements}

Both electronic and mechanical regular measurements, of a very high level of accuracy are planned throughout the three-year period of the tests. Exact geodetic measurements will supplement this work. Obviously, the evaluation of the measurements of deflections will be very sophisticated, and therefore method to be used will be the subject of a separate paper in the near future. Certainly, exact measurements of 
the strengthening element shift against the concrete surface will also be carried out.

\section{Conclusion}

The stands have been built up and the measurements are in progress. It is too early to publish results of measurements, but it seems that interesting conclusions on epoxy-resin creeping may be achieved. Topical developments of the measurement results will be published periodically.

\section{Acknowledgement}

Support has been provided for this project by the Grant Agency of the Czech Republic under project No.103/02/0749.

\section{References}

[1] Blais, C., Picard, A.: Flexural Strengthening of Reinforced Concrete Beams with Composite Plates. In Proc. Fourth Int. Conf. Short and Medium Span Bridges, Halifax, August 8-11, 1994, p. 919-929.

[2] Van̆ura, T., Mikš, L., Navara, L., Bajgar, O.: Efektizmost zesilováni železobetonu skleněnými tkaninami. (Effective- ness of Strengthening Reinforced Concrete with Fiberglass Fabrics. In Czech), Pozemní stavby, 11/1994, p. $460-461$.

Prof. Ing. Tomáš Vaňura, CSc.

e-mail: tvan@seznam.cz

Prof. RNDr. Ing. Petr Štěpánek, CSc.

e-mail: stepanek.p@fce.vutbr.cz

Ing. Švaříčková Ivana

e-mail: svarickova.i@fce.vutbr.cz

Dept. of Concrete and Masonry Structures

Prof. Ing. Jiří Adámek, CSc.

e-mail: adamek.j@fce.vutbr.cz.

Dept. of Testing Methods

TU Brno

Veveři 95

66237 Brno, Czech Republic 